\title{
Aneurysm of the internal carotid artery
}

\author{
Aneurisma da artéria carótida interna \\ Ludvig Hafner', Marcelo José de Almeidaㄹ, José Bitu Moreno ${ }^{3}$, Sílvio Antonio Bertachi Uvo ${ }^{4}$, \\ Amauri Porto Nunes ${ }^{5}$, Róvelton Utida ${ }^{6}$, Patrícia Uchôa 7 , Marília Frejuelo7
}

\begin{abstract}
Extracranial internal carotid artery aneuriysms (EICAA) are rare. There are few reports in the medical literature about its etiology, relating these aneurysms to atherosclerosis, arteritis and alterations due to trauma or after surgical procedure. The natural history of the disease has not been well-defined yet. However, the potential risk of embolism originating from the aneurysm - or even its rupture - indicates a need for intervention. We present the case of a seventy-one year old woman, who was diagnosed an aneurysm of three $\mathrm{cm}$ diameter of the right EICA, with throbbing headache complaints. After an unsuccessful attempt of endovascular treatment, we performed a surgical procedure with aneurysmectomy and primary end-to-end anastomosis near the skull base.
\end{abstract}

Keywords: aneurysm; internal carotid artery; surgery.

\section{Resumo}

Os aneurismas de artéria carótida interna ( $\mathrm{ACl}$ ) extracraniana são raros. Há poucos relatos na literatura médica quanto à sua etiologia, relacionando-os à doença aterosclerótica, às arterites e alterações decorrentes do trauma ou após procedimento cirúrgico. A história natural da doença ainda não está bem estabelecida. Entretanto, o potencial risco de embolia originário do aneurisma ou mesmo de sua ruptura indica necessidade de intervenção. Apresentamos o relato de caso de uma mulher de 71 anos diagnosticada com aneurisma de $3 \mathrm{~cm}$ de diâmetro da ACl extracraniana direita com queixas de cefaleia pulsátil. Após tentativa sem sucesso de tratamento endovascular, optou-se pelo tratamento cirúrgico com aneurismectomia e anastomose primária término-terminal próximo à base do crânio.

Palavras-chave: aneurisma; artéria carótida interna; cirurgia.

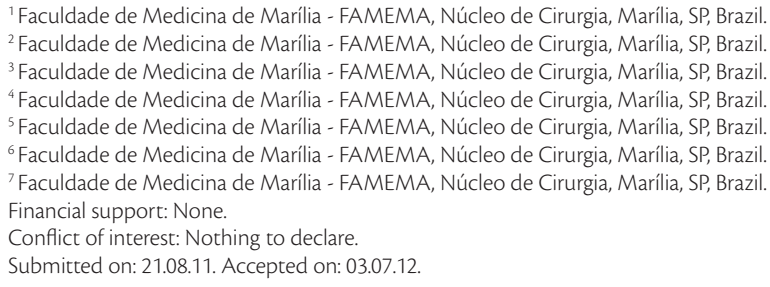




\section{INTRODUCTION}

Extracranial internal carotid artery (EICA) has about $8 \mathrm{~cm}$ long and extends from its bifurcation in the carotid bulb to the carotid canal. Aneurysms in this segment of the carotid artery are rare, accounting for less than $4 \%$ of the peripheral ones and, due to this fact, it is difficult to establish a natural history of the disease ${ }^{1,2}$. Clinically, it is presented as a palpable and a pulsatile mass in the neck about the mandibular angle ${ }^{3,4}$. Patients may be asymptomatic or present hoarseness, dysphagia, pain from nerve compression and neurological changes resulting from cerebral embolizations ${ }^{5}$. Because of the risk of stroke, rupture and compression of adjacent structures, surgical treatment is indicated.

The causes related to aneurysmal degeneration in the extracranial internal carotid are atherosclerosis, arteritis, fibromuscular dysplasia, trauma and disseccions ${ }^{6}$. There are several reports of external carotid artery pseudoaneurysms - or in their branches - and of EICA that occur as a complication of the tonsillectomy surgery or uvulopalatopharyngoplasty (used for the treatment of sleep apnea syndrome $)^{7}$.

Although with few descriptions, the open surgery, when indicated and used for ICA aneurysm, proved effectiveness. It presents variety of techniques, including primary anastomosis, derivations with the external carotid artery or arterial, vein or synthetic prostheses grafts ${ }^{8,9}$. The endovascular technique has been considered for high-risk patients and because of the benefit of being less invasive. Technical difficulties due to anatomical variations, diameters of used devices and arterial curvatures must be considered for the indication of the endovascular treatment ${ }^{10}$.

Next, we present a case description of this rare disease, as well as the treatment options that can be used.

\section{CASE REPORT}

Patient: 71 years-old, female, white, with pain in the neck, with slight numbness in the face, near the mandibular angle region, without other neurologic manifestations. She had hypertension and was using Enalapril $20 \mathrm{mg}$ twice daily. She also reported a previous surgery for tonsillectomy 12 months earlier for signs of recurrent tonsillitis (according to the patient). On physical examination, it was noticed a palpable and pulsatile mass, in the mandibular angle and in the oropharynx from the right side, with no other oropharyngeal changes. Computed tomography (CT) scan of the brain showed no alterations. However, Doppler ultrasound and magnetic resonance angiography confirmed the presence of an intracranial saccular aneurysm of $30 \mathrm{~mm}$ diameter. An angiography of the carotid arteries in cervical and intracranial regions showed an intracranial saccular aneurysm near the skull base, at the level of the second and the third cervical vertebrae (C2 and C3), with large arterial tortuosity (Figures 1 and 2). The angiographic of the contralateral carotid and vertebral arteries revealed no changes.

The first option was the drug-eluting stent Viabahn (Gore, USA) to exclude the flow in the aneurysm. For this purpose, it was inserted a guiding catheter type 8-F Soft Tip (Boston, USA) at the origin of ICA. However, it was not possible to pass the tab on the segment of distal ICA due to the tortuosity presented and, during the procedure, there was a detachment of the carotid intima-media thickness in the bifurcation region, requiring the stent (Wallstent) placement in order to avoid the increase of artery dissection.

After two weeks, the open surgery was performed. The procedure began with general anesthesia. Then, there was a arcuate submandibular incision with exposure of the patient's jaw and section in its horizontal portion, near the third molar, with lateral and upper movements, providing adequate exposure of the entire path of ICA, which allowed the surgeons to expose the aneurysm with repair of proximal ICA.

For the identification and repair of the distal internal carotid artery at the skull base, it was necessary to cut the styloid process. After an intravenous administration of 5,000 IU of systemic heparin sodium, there were the proximal clamping and the opening of the aneurysm, with identification of the distal segment of ICA, which showed no impair, and the arterial clamping near the skull base. After this correction, we observed that it was possible a primary anastomosis with the help of magnifying glasses, without the need of graft interposition. The suture was performed with 7-0 Prolene. The local hemostasis was achieved by gentle compression after flow restoration, and the superficial tissues were closed in layers on a $7 \mathrm{~mm}$ suction drain tube placed below the cervical fascia.

The patient was monitored in the intensive care unit and had no complications. On the first postoperative day (PO), she was awakened, without neurological deficit. Her drain was removed after 24 hours, and she was transferred to the infirmary. Diet and ambulation were started on the second postoperative day, and, on the fifth day, the patient was discharged. In her return, after 15 days, she had slight facial swelling, with no sign of facial palsy nor 


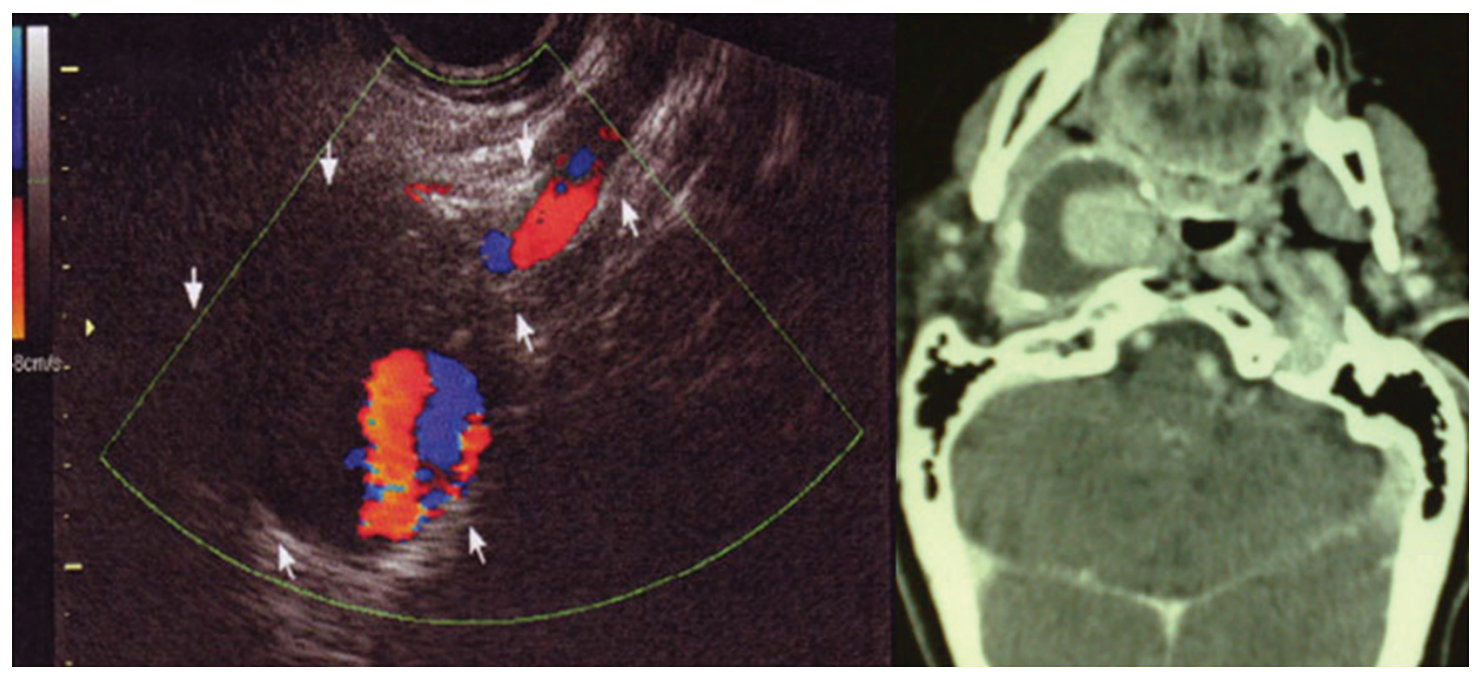

Figure 1. Ultrasound of the cervical region showing large internal carotid artery aneurysm, delineated by arrows. Magnetic Resonance Imaging (MRI) presents a large tumor with contrast inside, compatible with the aneurysm near the skull base.
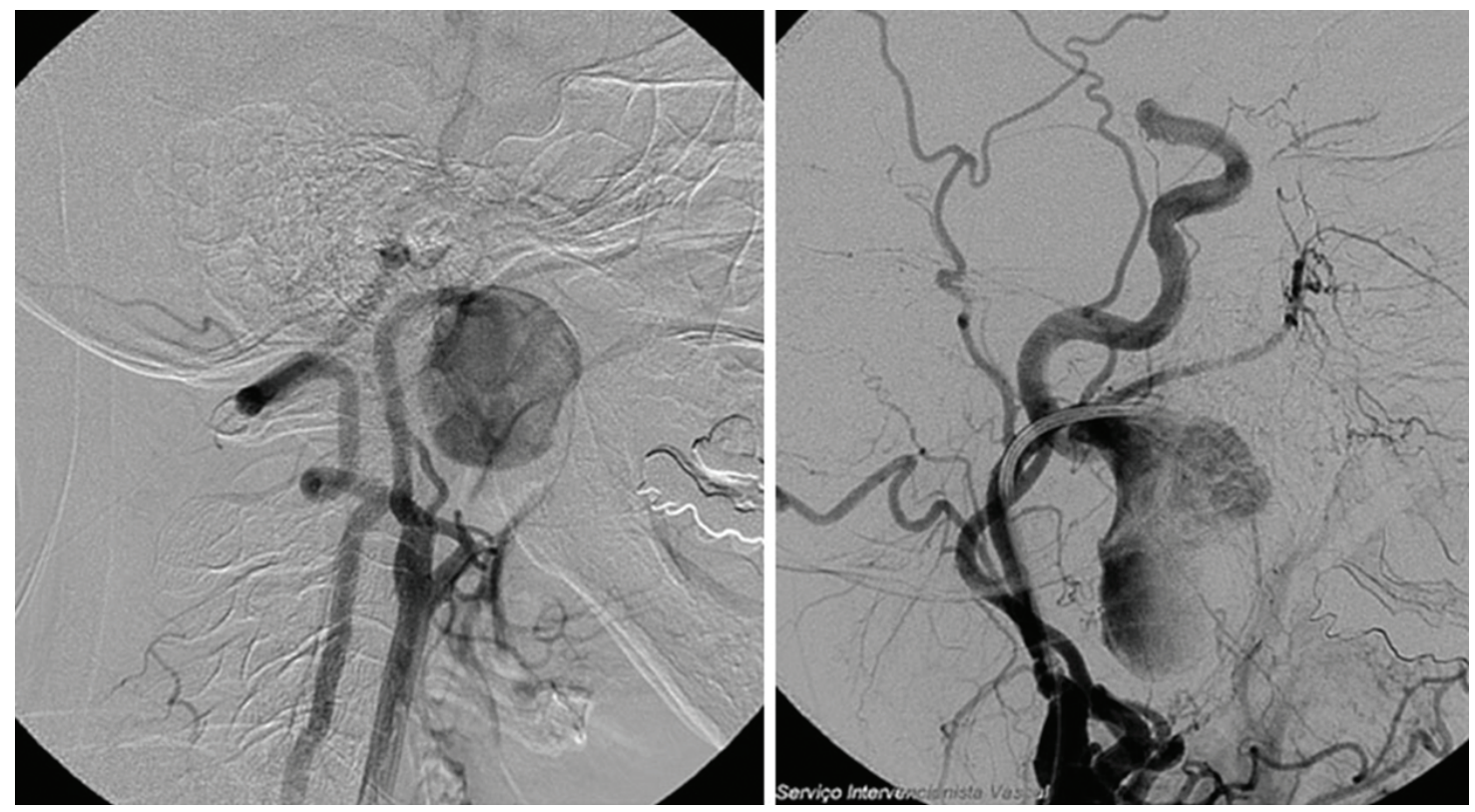

Figure 2. Selective arteriography showing internal carotid artery aneurysm near the skull base.

other nerves. The Doppler ultrasound performed at 30 days and at 6 months identified the Stent wellpositioned in the carotid bifurcation, and also the presence of flow across the whole path of ICA, with systolic and diastolic wave and velocities within the reference values and symmetrical, comparing both sides.

\section{DISCUSSION}

The patient described was previously attended by a general surgeon to treat the cervical and oropharyngeal cancer that bothered her, and ultrasound examination was essential for diagnosis. During the investigation of injuries of the inframandibular region, the Doppler ultrasound test is necessary before any intervention, such as biopsy, in order to avoid iatrogenesis ${ }^{11}$. Angiography, in this case, was extremely important to determine the location and the segment involved in treatment planning.

The most common reason reported for this type of aneurysm is atherosclerosis. However, several authors diagnosed trauma or tonsillectomy surgeries 
as important antecedents, that may be related to changes in both extracranial ICA and external carotid artery or its branches ${ }^{2,4}$. Although it is a rare complication of this surgery, the large number of procedures performed in the world should be taken into account, which could contribute to a sample of some relevance. Abnormalities in the path of the carotid arteries and their branches, as well as their relation to the tonsil's topography, could also be added to this kind of complication ${ }^{7}$. In this case, the primary cause of ICA aneurysm could be a local trauma resulting from the previous tonsillectomy surgery performed 12 months ago, or an atherosclerotic aneurysm isolated from EICA. Surgical excision of part of the aneurysm and pathologic evaluation failed to establish a precise etiologic diagnosis.

Therapeutic options include variety of techniques, such as stents, embolization and the alternatives of surgical approaches ${ }^{3}$. Although there is the attraction of performing an operation less invasive, endovascular interventions require favorable anatomy and flexible devices with an appropriate diameter (profile) in order to make a successful treatment ${ }^{7,10}$. In the external carotid artery aneurysms and their branches, the embolization is a feasible procedure, with an easier implementation. In this patient, endovascular treatment presented obstacles, such as the great tortuosity of the carotid and supra-aortic trunk vessels and morphological characteristics of the aneurysm, which hindered distal ICA catheterization, preventing the passage of the coated stent.

Concerning the open surgery, the curved incision skirting the jaw facilitated the exposure of the entire path of extracranial ICA. The lateral and upper movements of the jaw after section in the horizontal branch, before the third molar, prevents dislocation and opens a space that allows the work on the artery, reducing the risk of complications such as facial palsy and parotid lesions. Surgical treatment of ICA aneurysm includes alternatives using saphenous vein grafts, synthetic grafts or external carotid artery transposition of vessels. The rectification of ICA with end-to-end anastomosis was the chosen technique, and it proved to be effective in treatment. When anatomical dispositions allow, it becomes an attractive option, because it eliminates the need for vein grafts or the use of synthetic materials in order to shorten the time of occlusion and enable a single anastomosis. The microsurgical technique - with the help of magnifying glasses - increased quality to perform primary anastomosis of ICA near the skull base.

\section{REFERENCES}

1. Brito CJ. Aneurismas periféricos e esplâncnicos. In: Maffei FHA, Lastória S, Yoshida WB, Rollo HA, Giannini M, Moura R, editors. Doenças Vasculares Periféricas. 4. ed. Rio de Janeiro: Guanabara Koogan; 2008. p. 1311-47.

2. Jones WT, Pratt J, Connaughton J, Nichols S, Layton B, DuBose J. Management of a nontraumatic extracranial internal carotid aneurysm with external carotid transposition. J Vasc Surg. 2010;51(2):465-7. http://dx.doi.org/10.1016/j.jvs.2009.07.107

3. Mokri B, Piepgras DG, Sundt Junior TM, Pearson BW. Extracranial Internal carotid artery aneurysms. Mayo Clin Proc. 1982;57(5):31021. PMid:7043107.

4. Rittenhouse EA, Radke HM, Sumner DS. Carotid artery aneurysm. Review of the literature and report of a case with rupture into the oropharynx. Arch Surg. 1972;105(5):786-9. PMid:4673231.

5. Cury M, Greenberg RK, Morales JP, Mohabbat W, Hernandez AV. Supra-aortic vessels aneurysms: diagnosis and prompt intervention. J Vasc Surg. 2009;49(1):4-10. http://dx.doi. org/10.1016/j.jvs.2008.08.088

6. Rangasetty UC, Tyagi S, Mukhopadhyay S, Yusuf J, Gupta MD. Isolated extra-cranial internal carotid artery aneurysm in a young adult with Eale's disease. J Assoc Physicians India. 2003;51:830-2. PMid:14651154.

7. Testa JRG, Martin CN, Araújo K. Pseudo-aneurisma de artéria lingual tratado com embolização. Rev Bras Cir Cabeça Pescoço. 2008;37(1):60-1.

8. Galante JM, London JA, Pevec WC. External-internal carotid artery transposition for repair of multiple pseudoaneurysms from penetrating injury in a pediatric patient. J Pediatr Surg. 2009;44(3):e27-30. http://dx.doi.org/10.1016/j. jpedsurg.2008.11.059

9. Dorobisz AT, Rybak Z, Skóra J, et al. latrogenic injuries of the carotid arteries. Vasa. 2005;34(3):192-4. PMid:16184839.

10. DuBose J, Recinos G, Teixeira PG, Inaba K, Demetriades D Endovascular stenting for the treatment of traumatic internal carotid injuries: expanding experience. J Trauma. 2008;65(6):15616. PMid:19077655.

11. Garcia MRT, Chammas MC, Caiado AHM, Juliano AG, Leite CC, Cerri GG. Aneurisma da artéria carótida interna extracraniana: relato de caso. Radiol Bras. 2004;37(4):295-7. http://dx.doi. org/10.1590/S0100-39842004000400015

\section{Correspondence Ludvig Hafner Núcleo de Cirurgia-FAMEMA Rua Monte Carmelo, 800 CEP 17513-300 - Marília (SP), Brazi E-mail: Ihafner@terra.com.br}

Author information LH PhD. Professor of Angiology and Vascular Surgery, Faculdade de Medicina de Marília, Marília, Brazil. Member, Sociedade Brasileira de Angiologia e de Cirurgia Vascular (SBACV).

MJA PhD. Professor of Angiology and Vascular Surgery, Faculdade de Medicina de Marília, Marília, Brazil. Member, Sociedade Brasileira de Angiologia e de Cirurgia Vascular (SBACV). JBM PhD. Professor of Angiology and Vascular Surgery, Faculdade de Medicina de Marília, Marília, Brazil. Member, Sociedade Brasileira de Angiologia e de Cirurgia Vascular (SBACV)

SABV PhD. Professor of Head and Neck Surgery, Faculdade de Medicina de Marília, Marília, Brazil. Member, Sociedade Brasileira de Cirurgia de Cabeça e Pescoço (SBCCP) APN PhD. Professor of Angiology and Vascular Surgery, Faculdade de Medicina de Marília, Marília, Brazil. Aspiring member, Sociedade Brasileira de Angiologia e de Cirurgia Vascular (SBACV). 
RU Former resident physician (Angiology and Vascular Surgery), Faculdade de Medicina de Marília, Marília, Brazil. Aspiring member, Sociedade Brasileira de Angiologia e de Cirurgia Vascular (SBACV).

PU, MF Resident physician (Angiology and Vascular Surgery), Faculdade de Medicina de Marília, Marília, Brazil. Resident member, Sociedade Brasileira de Angiologia e de Cirurgia Vascular (SBACV).

Authors' contributions Conception and design: $\mathrm{LH}, \mathrm{MJA}$, JBM, SABU, APN Analysis and interpretation: $\mathrm{LH}$ Data collection: RU, PU, MF Writing the article: $\mathrm{LH}$

Critical revision of the article: MJA Final approval of the article*: LH, MJA, JBM, APN, RU, MF, PU, SABU Statistical analysis: MJA Overall responsibility: LH, MJA *All authors have read and approved the final version submitted to I Vasc Bras. 